\title{
O controle dos medicamentos anoréticos: mais um conto para as calendas gregas?
}

\section{The control of anorectic drugs: another tale for the Greek calends?}

Em 1993, uma comissão designada através de portaria do Ministro da Saúde e composta por representantes da Sociedade Brasileira de Vigilância de Medicamentos, Associação Médica Brasileira, Sociedade Brasileira de Endocrinologia e Metabologia, Associação Brasileira de Estudos da Obesidade e Sociedade Brasileira de Farmacologia e Terapêutica Experimental concluiu, entre outras coisas, que:

"I.1 - O Ministério da Saúde não mais deve permitir a existência no mercado de produtos acabados à base de substâncias tipo-anfetamina (dietilpropiona ou anfepramona, mazindol, $d$-l-fenfluramina, d-fenfluramina e outros) quando associadas às substâncias benzodiazepinicas. O registro dos atualmente existentes deve, portanto, ser cancelado."

Mas nada aconteceu em seguida!

Em 1994, o Conselho Federal de Medicina (Resolução 1404/1994) condenava os anoréticos, com os seguintes dizeres:

"Considerando que o uso de anfetaminas, isoladamente ou em associação com... finalidade exclusiva de tratamento de obesidade ou de emagrecimento, tem causado graves riscos à saúde humana (...)".

Idêntica providência foi tomada pelo Conselho Federal de Farmácia (Resolução no 262 de 16 de setembro de 1994).

Nada Aconteceu!

Desde a década de 1980, o International Narcotics Control Board (INCB), órgão ligado à ONU, apontava o Brasil como utilizando em excesso as substâncias anoréticas anfepramona, fenproporex e mazindol. Fomos apontados como país com uso irracional das mesmas, estando entre os primeiros do mundo em consumo através de prescrições, devido a uma legislação permissiva ${ }^{1}$.

Nada aconteceu!

No início do segundo milênio, a Associação Médica Brasileira, Associação Brasileira de Psiquiatria, Associação Brasileira de Estudos do Álcool e Outras Drogas, Coordenação de Saúde Mental do Ministério da Saúde, Sociedade Brasileira de Vigilância de Medicamentos, Sociedade Brasileira de Endocrinologia, Conselho Federal de Farmácia, Conselho Federal de Medicina e a Secretaria Nacional de Vigilância Sanitária voltam à carga e distribuem um cartaz educativo descrevendo o uso dos medicamentos anoréticos como um erro técnico, sem justificativa, podendo mesmo causar sérios danos à saúde.

Nada aconteceu!
O uso de anfetaminas anoréticas para fins estéticos (perda de peso) já foi objeto de fortes críticas em países como Espanha, Estados Unidos, Inglaterra e vários países latino-americanos ${ }^{2}$. Além disso, trabalhos científicos de autores brasileiros de várias cidades Pelotas (RS), São Paulo (SP), São Caetano do Sul (SP), Diadema (SP), Ribeirão Preto (SP), Belo Horizonte (MG), Goiânia (GO), Fortaleza (CE), São Luiz (MA) e Belém (PA) - também criticam o uso irracional destes agentes anoréticos (para referências completas destes trabalhos, ver Nappo et al., 2010).

E nada foi feito!

Em 2008, foi criado na ANVISA o Sistema Nacional de Gerenciamento de Produtos Controlados (SNGPC), um programa de amplitude nacional exigindo o envio semanal de dados às autoridades de vigilância sanitária.

Ao que parece, aconteceu algo: segundo o SNGPC, o número de prescrições de anfepramona, fenproporex e mazindol caiu de maneira acentuada.

Mas também outro fato ocorreu: aumentaram tremendamente as prescriçôes de fluoxetina ${ }^{3}$, muito possivelmente com a mesma finalidade estética (e não necessidade médica), apesar das reações adversas causadas por este antidepressivo.

As reaçōes adversas produzidas pela anfepramona, fenproporex e mazindol já foram há muito descritas ${ }^{4}$ e, além disso, as três só podem ser vendidas com embalagem contendo faixa preta, recomendação da ONU para produtos indutores de dependência.

É marcante que, devido a estas sérias conseqüências, o governo português, em 1999 - há mais de 10 anos, portanto - proibiu a venda de tais substâncias, declarando que:

“(...) notificaçôes de reaçôes adversas graves em pacientes medicados com preparaçôes magistrais para o tratamento de obesidade; (...) substâncias cujo perfîl de segurança não está suficientemente documentado em termos cientificos (...) fica proibida a prescrição e preparação de medicamentos (...) contendo anfepramona [e/ou] fenproporex (...)".

Infelizmente, esta decisão do Ministério da Saúde de Portugal passou em brancas nuvens no Brasil.

E nada aconteceu!

A sibutramina é a quarta droga anorética, a mais recente no mercado e também muito prescrita no Brasil. Foram publicados, recentemente, os resultados do estudo SCOUT ( Sibutramine 
Cardiovascular OUTcomes), patrocinado pelo laboratório Abbott, que comercializa a substância, mostrando um aumento em 16\% da possibilidade de ocorrência de sérios eventos cardiovasculares adversos ("ataque cardiaco, derrame, parada cardiaca com ressuscitação ou morte") em comparação com pacientes recebendo placebo. Além disso, a perda de peso conseguida foi muito pequena, não justificando o uso da sibutramina.

Devido aos dados do estudo SCOUT, as agências de vigilância sanitária dos Estados Unidos (FDA), comunidade européia (EMEA), Canadá (Health Canada), Austrália (TGA) e Arábia Saudita decidiram pela retirada da sibutramina do mercado ${ }^{5}$.

Em 2011, no último capítulo desta calenda, a ANVISA propõe, através de duas consultas públicas, a retirada do mercado das quatro substâncias anoréticas. Após estas duas consultas, a situação continua indefinida. Alegam aqueles que defendem a permanência no mercado das quatro substâncias que os pacientes com obesidade mórbida (IMC acima de 40) ficarão sem nenhum recurso terapêutico, e para eles a obesidade é um sério fator de risco cardíaco.
Mas é importante que sejam levados em consideração dois fatos relacionados a este ponto:

A imensa maioria das prescrições de agentes anoréticos dá-se por fatores estéticos (perder peso sem finalidade médica);

É, no mínimo, questionável a utilização de agentes terapêuticos com reconhecido efeito tóxico cardiovascular para pacientes que já apresentam este risco devido à obesidade excessiva.

Em síntese, é sobejamente conhecido o forte lobby visando a manutenção de tais substâncias no mercado. Por outro lado, desde há tempos a comunidade científica mundial e sociedades médicas e farmacêuticas brasileiras posicionam-se contra estes status quo cientificamente inaceitável. Esperamos que desta vez a verdade científica prevaleça.

E. A. Carlini

CEBRID - Centro Brasileiro de Informações sobre Drogas Psicotrópicas Universidade Federal de São Paulo (UNIFESP)

Financiamento e conflito de interesses

\begin{tabular}{|c|c|c|c|c|c|c|c|}
\hline $\begin{array}{c}\text { Membro } \\
\text { do grupo } \\
\text { de } \\
\text { autores }\end{array}$ & $\begin{array}{l}\text { Local de } \\
\text { trabalho }\end{array}$ & $\begin{array}{l}\text { Verba de } \\
\text { pesquisa }\end{array}$ & $\begin{array}{c}\text { Outro } \\
\text { apoio à } \\
\text { pesquisa } \\
\text { ou } \\
\text { educação } \\
\text { médica } \\
\text { continuada }\end{array}$ & $\begin{array}{c}\text { Honorários } \\
\text { de } \\
\text { palestrante }\end{array}$ & $\begin{array}{l}\text { Participação } \\
\text { acionária }\end{array}$ & $\begin{array}{c}\text { Consultor/Conselho } \\
\text { consultivo }\end{array}$ & Outro $^{3}$ \\
\hline Carlini EA & $\begin{array}{l}\text { UNIFESP, } \\
\text { CEBRID }\end{array}$ & - & - & - & - & - & - \\
\hline \multicolumn{8}{|l|}{ * Modesto } \\
\hline ** Significat & & & & & & & \\
\hline
\end{tabular}

Referências

1. INCB - International Narcotics Control Board. Stimulants in schedule IV of the 1971 Convention used as anorectics. Report INCB. Vienna; 2005. p.26. 2. Nappo AS, Carlini EA, Araujo MF, Moreira LF. Prescription of anorectic and benzodiazepine drugs through notification B prescription in Natal, RG Norte. Brazil. Braz J Pharm Sci. 2010; $\underline{46}$ :297-303.

3. Carlini EA, Noto AR, Nappo SA, Sanchez ZV, Franco VL, Silva LC, Santos VE, Alves DC. Fluoxetina: indícios do uso inadequado. J Bras Psiquiatr. 2009;58;97100 .

4. Nappo SA. Consumo de anorexigenos tipo-anfetamina (dietilpropiona, fenproporex, mazindol) e fenfluramina no Brasil: prejuízo ou benefício para a saúde? J Bras Psiquiatr. 1992; $\underline{41: 417-21 .}$

5. WHO - World Health Organization - Regulatory matters. Sibutramine: suspension of marketing authorizations recommended in the European Union e Market withdrawal due to risk of serious cardiovascular events. WHO Pharmaceuticals Newsletter. 2009/2010;6: pg 9-10, 2010;n6: pg 4. 